\title{
CONSTRUÇÃO DE UM CURRÍCULO INTEGRADO DE ENFERMAGEM
}

\author{
BUILDING AN INTEGRATED CURRICULUM FOR NURSING
}

\author{
Regina Aurora Trino Romano ${ }^{1}$ \\ Luiza Maria Piazzi Papa ${ }^{1}$ \\ Gertrudes Teixeira Lopes ${ }^{1}$
}

RESUMO: Durante as duas últimas décadas, a sociedade brasileira passou por grandes transformações no campo político, ideológico e econômico. Essas mudanças deixaram suas marcas na sociedade, especialmente na saúde da população. A formação do Enfermeiro, baseada na Lei 5540/68 e no Parecer 163/72, não mais acompanha as demandas que a população reivindica. A partir de 1992, a Faculdade de Enfermagem da UERJ - FEUerj intensifica o movimento de reflexão sobre o processo de ensino-aprendizagem em busca de transformar a realidade em que vive. A realização desse projeto apresenta duas razões importantes e complementares: o desejo dos docentes e discentes da FEUerj em elaborar um currículo que busque a formação de um Enfermeiro que articule ensino-trabalho-comunidade, teoria e prática, fundamentado em uma Teoria Crítica da Educação, na linha de PROBLEMATIZAÇÃO, e o cumprimento do Parecer 314/94 do então CFE e da Portaria MEC no 1171/15/dez/94. A partir de debates, definiu-se o perfil profissional tendo em vista o meio social onde a profissão se realiza e as características do alunado; determinação de áreas ou conjunto de atribuições, de acordo com a adequação da prática profissional, hierarquização dos conceitos, processos, etc., que no processo de "síntese e classificação" dos conhecimentos resulta em uma árvore encadeada e relacionada como se fosse uma rede. Na primeira fase do estudo do currículo diagnosticou-se como condição precipua a "DESCONTEXTUALIZAÇÃO" do curriculo vigente e os "NÓS" a serem enfrentados para levar a cabo a proposta de Reforma Curricular. Implementou-se o processo de Capacitação Pedagógica para professores, oficinas de trabalho, levantamento do perfil atual e o desejável, seminários, sistematização dos desempenhos, habilidades e princípios, identificação das áreas que compõem o Currículo Integrado, localização das disciplinas dentro das áreas e a articulação entre disciplinas profissionalizantes e outras atividades. Com base nesta ta. etapa do trabalho na pedagogia problematizadora, construiu-se o instrumento "Levantamento do Perfil Profissional do Curso de Graduação em Enfermagem", identificando-se os desempenhos e princípios que os sustentam em cada disciplina vigente, tornando claro o perfil atual e o desejável pelos docentes e discentes.

UNITERMOS: Currículo integrado - Educação crítica - Pedagogia da problematização.

${ }^{1}$ Enfermeiras, Professoras da Faculdade de Enfermagem da UERJ 
ABSTRACT: During the last two decades, Brazilian society has gone through great changes into political, ideological and economical fields. These changes left their strings into society, specially in population health. The nurse formation based on the Law $n^{\circ} 5540 / 68$ and on the Statement $n^{\circ} 163 / 72$, no more meets population demands. Since 1992, the Nursing Faculty of UERJ - FEUerj intensifies the reflection movement upon teaching-learning process searching for transforming its own reality. The making of this project presents two complementary and important reasons: FEUerj docents and discents' desire in elaborating a curriculum which searches for nurses' formation that articulates teaching-work-community, theory and practice, based on a Critical Theory of Education, on the line of PROBLEMATIZATION, and the accomplishment of Statement $n^{\circ} 314 / 94$ from the CFE and from the Letter of Order MEC $n^{\circ}$ $1171 / 15 /$ dez/94. From debating, the professional profile has been defined from the social environment where the profession is performed and the alumnate's characteristics; area determination or group of attributions, according to professional praxis adequation, concept hierachization, processes, etc., which in the process of 'classification and syntheses' of knowledge results into a netlike chained and related tree. In the first phase of the curriculum study, it has diagnosed as principal condition, the actual curriculum 'DECONTEXTUALIZATION' and the 'US' to be faced to lead it to an end the Curriculum Reformulation Proposal. The Process of Pedagogical Abilitation for professors, workshops, researches on the desirable and present profile, seminars, performance, abilities and principles systematization, identification of areas which compose the integrated curriculum, subjects localization into areas and articulation between professional subjects and other activities, has been implemented. Based on this work on the problematized pedagogy first step, an instrument 'Research on the Professional Profile for the Nursing Graduation Course', was built, identifying the performances and principles which sustain them on each subject making the present profile clear and desirable to docents and discents.

KEYWORDS: Integrated curriculum - Critical education - Problematization of pedagogy. 


\section{INTRODUÇÃO}

O último currículo mínimo de enfermagem anterior à Portaria Ministerial $n^{0}$ 1721/94 data de 1972. Durante estas duas décadas, o país passou por grandes transformações, seja no campo da política com mudança de regimes de governo, seja no campo ideológico e principalmente no econômico, quando fomos submetidos à testagem de vários planos econômicos e diferentes moedas.

Essas mudanças processadas nas esferas política, ideológica, econômica, com certeza deixaram suas marcas na sociedade, especialmente na saúde da população, evidenciadas por um povo mais pobre, faminto e, portanto, doente.

Ninguém desconhece que a formação do enfermeiro, baseada na Lei $5540 / 68$ e no Parecer 163/72, não mais acompanhava as demandas oriundas da sociedade. Neste aspecto, urge não só a mudança do currículo em termos de carga horária e disciplinas, mas principalmente a mudança de paradigma.

Algumas discussões vinham se dando nesta última década, na tentativa de uma aproximação entre a oferta e a procura da saúde, com destaque para a formação e utilização de recursos humanos.

Nesta linha de ação, o Relatório da $8^{a}$ Conferência Nacional de Saúde ${ }^{7}$, 1986 já preconizava a "formação dos profissionais de saúde integrada ao Sistema de Saúde , regionalizado e hierarquizado".

A Lei Orgânica da Saúde, de $1990^{11}$, determina, como uma das atribuições comuns da União, dos Estados e do Distrito Federal, a "participação na formulação e na execução da política de formação e desenvolvimento de recursos humanos para a saúde ${ }^{8}$.

Neste sentido, a $9^{a}$ Conferência Nacional de Saúde $(1992)^{12}$ inclui, como ação para a efetiva implantação de uma política de recursos humanos para o SUS, a revisão dos currículos profissionais, ajustando-os às realidades sociais, étnico-culturais, ao quadro epidemiológico da população, garantindo a graduação de profissionais com visão integral, comprometimento social e formação geral. Esta adequação deverá propiciar a integração do aparelho formador com o sistema prestador de serviços.

O grupo de trabalho - Aperfeiçoamento e Humanização das Ações Assistenciais, através do documento Distrito Sanitário ${ }^{8}$, enfoca a necessidade de se repensar a prática de atendimento à clientela oferecida pelos profissionais de saúde, dentro das concepções de saber, tarefas e papéis. Prossegue afirmando: "Para que se modifique a relação entre profissional de saúde e clientela é necessário reavaliar o enfoque de supervalorização dos aspectos técnicos dos treinamentos, onde são desconsideradas todas as outras questões importantes envolvidas no atendimento à saúde". As Instituições formadoras de recursos humanos para a saúde, tradicionalmente, tratam as questões do corpo dentro de uma perspectiva biológica e segmentada. É absolutamente importante considerar o corpo como uma totalidade e cuidar dele inserido num contexto sócio-cultural. 
Enfatiza ainda que a metodologia educacional usada é ineficaz, o que denota a necessidade de práticas alternativas. Declara a premência de se adotar uma metodologia nova, que seja abrangente e possibilite a participação de todos os profissionais envolvidos, levando a um novo tipo de relação com a clientela e com a própria equipe de saúde.

Nesta linha de pensamento, a realização deste projeto alicerça-se em duas vertentes importantes que se complementam: a primeira é o desejo dos docentes e discentes da Faculdade de Enfermagem da Universidade do Estado do Rio de Janeiro - F. Uerj, em elaborar um currículo comprometido com a formação de um enfermeiro capaz de articular dinamicamente ensino-trabalhocomunidade, teoria e prática, fundamentado na Teoria Crítica da Educação, na linha de PROBLEMATIZAÇÃO, a segunda visa o cumprimento do Parecer 314/94 de 06/04/94 do então CFE, publicado no DOU de 28/11/94, Seção I., p. 17.991 e da Portaria MEC n 1171 (15/DEZ/94), publicada na p. 1981, que fixa os mínimos de conteúdo e duração do Curso de Graduação em Enfermagem.

A partir dos princípios e das estratégias assumidas como norteadoras do processo de construção do novo currículo, a F.E. Uerj elaborou os seus objetivos de trabalho:

\section{Objetivo Geral}

Transformar o objeto, a estrutura e a metodologia presentes no currículo de graduação em Enfermagem da F.E. Uerj.

\section{Objetivos Especificos}

1. Adotar uma Teoria Crítica da Educação, dentro da opção pedagógica de problematização da realidade, que permita a reflexão, a crítica e o conhecimento indispensáveis à transformação da prática profissional do Enfermeiro;

2. Adotar como paradigma: Aprendizagem é uma relação dialética e dinâmica entre o sujeito que aprende e o objeto a ser aprendido, tendo o professor como mediador desse processo.

3. Utilizar como eixo norteador o Processo de Trabalho em Saúde/Enfermagem e os determinantes do Processo Gerador Saúde/Doença;

4. Integrar os conteúdos curriculares em áreas de conhecimentos que sustentem um conjunto de práticas;

5. Adotar uma metodologia que privilegie uma efetiva integração entre ensino-serviço, educação-trabalho; considerando o "Trabalho" enquanto um princípio pedagógico, tendo como pano de fundo as características sócio-culturais do meio em que o processo de ensino-aprendizagem se desenvolve;

6. Implementar um currículo de estrutura integrada que tenha a educação como referência no preparo do cidadão para uma ação transformadora da prática social; 


\section{PROCESSOS DE DISCUSSÃO CURRICULAR NA F.E.Uerj}

A Faculdade de Enfermagem da Uerj, representada por seus professores e alunos, há muito tempo tinha clareza de que o atual currículo não atendia mais as demandas de saúde da população.

Nessa perspectiva, a partir de 1992, desenvolveu vários movimentos para discussão e reflexão sobre o seu processo de ensino-aprendizagem. Assim, em abril desse ano, a direção da faculdade, que já vinha participando ativamente dos Seminários de Currículo da Associação Brasileira Enfermagem - ABEn, criou o Fórum Permanente para a Formação do Enfermeiro e constituiu uma comissão representativa dos três segmentos da instituição: docente, discente e técnico administrativo.

A Comissão indicada decide organizar a $1^{\text {a }}$ Oficina de Trabalho para elaboração do Plano Quadrienal da unidade acadêmica para a gestão 1992 1996.

Nessa ocasião, acordou-se que as propostas pedagógicas deveriam partir dos Principios Constitucionais da Organização do Sistema de Saúde e dos direitos e deveres de cidadania da população brasileira .

Os resultados dessa Oficina apontam diretrizes e metas para o ensino, a pesquisa e a extensão. Com relação ao ensino, a opção foi por uma Teoria Crítica com enfoque na problematização, na articulação interdisciplinar e interdepartamental e pela reformulação do currículo consoante as diretrizes do Sistema Único de Saúde (SUS) e o atendimento das necessidades da comunidade, buscando a formação de um enfermeiro capaz de atuar integralmente em nível de excelência e em pleno exercício da cidadania. $A$ pesquisa e a extensão seriam desenvolvidas articuladamente com o ensino, o serviço e a comunidade e o seu produto teria como objetivo a transformação da realidade.

Nesse esforço, surge a Oficina de Criação com a finalidade de promover, estimular e socializar todas as propostas pedagógicas que pudessem influir e possibilitar um melhor rendimento dos corpos docente, discente e técnicoadministrativo, através de inventos, novas metodologias e técnicas de ensinoaprendizagem. A Oficina de Criação abre um leque de possibilidades e tem um de seus espaços direcionados para o pedagógico, o qual inclui projetos como: análise institucional, cursos, análise do processo de avaliação pedagógica e planejamento do currículo integrado.

A análise institucional foi realizada em parceria com a FIOCRUZ $^{19}$ e desenvolvida durante dois anos, tendo como princípio fazer com que os sujeitos (pessoal de enfermagem) "apropriem-se daquilo que eles mesmos produziram, reconhecendo o compromisso com as decisões e direções que suas práticas pontuam"..., além de" desencadear um processo de análise enquanto possibilidade de representação e representificação da história institucional, de tal forma que deslocamentos sejam produzidos e durante este processo transformações sejam operadas" (Dâmaso et al, 1994) ${ }^{15}$. 
Um dos resultados deste trabalho, o qual se deu a partir do esforço conjunto dos professores, enfermeiros, sociólogo e psicólogos, foi a identificação do perfil institucional da Faculdade de Enfermagem, que, segundo este grupo, representa duas instituições: a de saúde e a de educação.

Neste sentido, chegou-se a algumas conclusões importantes, tais como: o feminino da enfermagem como objeto de vigilância e dominação; o Magistério e a Enfermagem - profissões femininas por excelência - e que acabam por atualizar uma dimensão do trabalho como extensão do lar; a construção do objeto de sua práxis - o cuidado ao doente a partir de suas necessidades básicas - centrado na pluralidade de disciplinas que emprestam à Enfermagem um pouco do seu campo de conhecimento (enquanto ciência "o saber da enfermagem" parece esvaziado de objeto justamente por não responder aos parâmetros cientificistas clássicos); as mutilações e contenções sofridas pelos enfermeiros durante a formação e no campo da assistência e, ainda, a sedução produzida pelo poder médico, que serve de espelho, no campo da especialização e da tecnologia dos aparelhos, o que impede a enfermagem de afirmar e construir sua singularidade, além de outras conclusões ligadas ao contexto hospitalar e à integração docente-assistencial (Dâmaso et al, 1994) ${ }^{16}$.

Paralelamente, um outro evento de suma importância foi deflagrado na Faculdade de Enfermagem, vislumbrando a apropriação de uma pedagogia que desse conta das aspirações dos docentes, discentes e de um contexto sóciocultural e da saúde que vinha, ao longo do tempo, se transformando. Esse evento, materializado nos cursos de Capacitação Pedagógica, contou com a parceria da Escola de Formação Técnica em Saúde "Enfermeira Isabel Santos", da Secretaria de Estado de Saúde do Rio de Janeiro, que ofereceu professores e todo material didático. Em resposta a este investimento, contamos com a qualificação aproximada de mais de $80 \%$ do corpo docente. Estes cursos ofereceram vagas para os enfermeiros do Hospital Universitário "Pedro Ernesto" - HU-PE, professores da Escola de Formação Técnica em Saúde, alunos do Curso de Licenciatura em Enfermagem da Uerj, além de outras instituições de ensino e serviços de saúde do Estado do Rio de Janeiro. Em setembro de 1994, aconteceu a $2^{\text {a }}$ Oficina de Trabalho com o tema "Nós e os Nós da Avaliação", como parte seqüencial das atividades previstas pelo Fórum Permanente para a Formação Integral do Enfermeiro que identificou a avaliação como um dos problemas a ser tratado sob o ponto de vista institucional. Também, cuidou-se para que os papéis e as diferenças individuais do avaliador e do avaliado fossem considerados, tendo como proposta a contextualização histórica da avaliação, objetivando manter o que vale ser preservado, desprezar o inócuo e exorcizar o improdutivo e o prejudicial. O produto decorrente dos resultados alcançados com a Análise Institucional, as Capacitações Pedagógicas e a Avaliação Pedagógica, além da expectativa de oficialização do Novo Currículo Mínimo de Graduação em Enfermagem, levou o corpo docente, em reunião realizada no dia 28.10 .94 , a decidir por uma reforma curricular a partir de 
uma concepção pedagógica radical. $O$ interesse manifestado pelos docentes durante a reunião foi seguido da decisão política da Direção em formar uma comissão para dar andamento a essa ambiciosa proposta. Dessa forma, no dia 08.12.94, a Diretora da Faculdade de Enfermagem, "considerando as decisões do corpo docente de 28.10.94, e do Conselho Departamental datado de 15.12.94, e com base nos vários eventos e discussões acerca do Estudo para a Reforma Curricular do Curso de Graduação em Enfermagem, referendando a proposta no sentido processual e dinâmico independente de gestões administrativas, cria a Comissão de Trabalhos para a Elaboração e Acompanhamento do Plano Estratégico da Reforma Curricular do Curso de Graduação em Enfermagem da Uerj, através da Portaria nº 011 / FENF / 94, ao tempo em que designa com atribuições definidas os membros de coordenação, execução, consultivo, assessoria técnica e representação estudantil. Desta forma, ficou estipulado o prazo de um ano para o cumprimento da fase de elaboração do Plano Estratégico, a saber: etapas de preparação da comissão, montagem do projeto, aprovação da proposta, implantação e desenvolvimento das Oficinas de Trabalho.

\section{MARCO CONCEITUAL}

$\mathrm{Na}$ construção do marco conceitual, coube questionar que linha da Educação poderia vir a contemplar as questões anteriormente levantadas de: "estreita relação entre processos de formação e trabalho em enfermagem", "práticas que atendam às demandas de saúde da população e aos princípios contidos na Lei Orgânica de Saúde". Que concepção pedagógica promoveria "enfermeiros dotados de competência técnico-científica e política para intervir no quadro epidemiológico do país"? Que processos metodológicos e estrutura curricular propiciariam articulação dinâmica entre ensino-trabalho-comunidade, teoria e prática? Que corrente pedagógica consideraria o aluno enquanto sujeito que apreende ativamente "objetos" que tenham relevância para prática profissional, mediatizados por um outro sujeito-professor? Enfim, qual a estrutura do objeto a ser assimilado?

Só uma concepção educacional essencialmente democrática, que buscasse resgatar o conceito e a prática da cidadania e que permitisse a crítica e a reflexão, poderia atender às questões levantadas.

Azevedo ${ }^{4}$, em sua dissertação de Mestrado, interroga:

"... Traduzindo-se processo de aprendizagem como uma relação dinâmica entre sujeito e objeto, como se processa essa relação? Como o sujeito aprende?"..."O sujeito aprende a partir de sucessivas aproximações à estrutura do objeto e estas aproximações são alcançadas pela aplicação ativa dos esquemas de assimilação de que dispõe e a partir de sua percepção social inicial" ${ }^{4}$. 
Estes princípios apontariam na direção de um modelo pedagógico sustentado pela Psicologia Genética de Jean Piaget, pela Sociologia e pela Antropologia Social. A autora aborda com propriedade a relação sujeito-objeto: “... nenhum dos dois é caixa vazia. Se, de um lado está o sujeito com seus esquemas de assimilação e padrões culturais, do outro está o objeto com uma estrutura própria." Quanto à estruturação dos conteúdos, qualquer técnica tem seus "porquês" na estrutura de conhecimento que lhe dão suporte, indicando sua razão de ser; os conhecimentos que justificam as técnicas relacionam-se de forma organizada e hierarquizada desde os mais abrangentes aos mais especificos. "... de maneira a formar uma rede de conhecimentos encadeados e relacionados entre si" (Azevedo, 1991) ${ }^{4}$.

Assim, acreditamos que a concepção de educação adequada às nossas inquietações, à busca da cidadania e da reconstrução social, seja a "Educação Crítica", na medida em que o significado de "crítica" como construtor filosófico está relacionado à categoria de totalidade.

A educação crítica, segundo Kosik, está voltada para a construção do conhecimento que não consiste num mero "acrescentamento sistemático de fatos, e de noções a outras noções, mas num entendimento da realidade como totalidade, partindo-se do todo para as partes e das partes para o todo, dos fenômenos para a essência e da essência para os fenômenos" 23 .

Partindo do entendimento que: "em um mundo de mudanças rápidas o importante ... é o aumento da capacidade do aluno - agente da transformação social - para detectar problemas e buscar soluções criativas" ${ }^{19}$, desenvolver esta capacidade no aluno requer adotar uma pedagogia crítica-problematizadora; que tenha como ponto de partida a observação e uma primeira leitura da realidade, ("visão sincrética") seguida da identificação das variáveis que determinam a situação problema (pontos chave), em um terceiro momento, quando se irá perguntar o porquê das coisas observadas, confrontando a realidade com sua teorização, sendo então capaz de formular hipóteses de solução (provas de viabilidade). Estas serão confrontadas com as limitações da própria realidade ("visão sintética").

Adotar a pedagogia da problematização irá gerar aprendizagem ligada aos aspectos significativos da realidade e ao desenvolvimento das habilidades de observação, análise, extrapolação e resolução de problemas. Nesta concepção, aprender é um ato de conhecimento da realidade concreta e só tem sentido se resulta de uma aproximação crítica desta realidade, à qual se chega pelo processo de compreensão, reflexão e crítica (Saviani, 1982) ${ }^{30}$.

Este processo requer uma relação dialógica na relação professor-aluno, onde ambos caminham juntos na busca da leitura do mundo, da compreensão do contexto (Freire e Shor, 1986) ${ }^{18}$. A metodologia dialógica deve ser essencialmente problematizadora, cujas bases se encontram na ação-reflexãoação e na busca do conhecimento crítico. 


\section{METODOLOGIA}

A construção da Estrutura de um Currículo Integrado exige o entendimento de um processo que deve ser desenvolvido vencendo as tendências estereotipadas de reprodução de vivências anteriores ou, como diz Davini, "não existem receitas padronizadas"9. Esta autora aconselha: é necessário que se tenha bem claro as atribuições "que estão e que deveriam estar implicadas na prática social de uma profissão" além daquelas consideradas "DESEJÁVEIS", desde que ajustadas à demanda dos serviços e da sociedade.

A concretude de um projeto com essas características depende de amplos debates por seus atores, para se chegar às seguintes etapas preconizadas por Davini (in Capacitação Pedagógica para INSTRUTOR/SUPERVISOR, 1989) ${ }^{9}$ :

- definição do perfil profissional, considerando o meio social onde a profissão se realiza e as características do alunado;

- determinação de áreas ou conjunto de atribuições, de acordo com as adequações ou consenso da prática profissional;

- hierarquização dos conceitos, processos, etc. que, no processo de "sintese e classificação" dos conhecimentos, resulta em uma árvore encadeada e relacionada, como se fosse uma rede. A isso chama-se "estrutura de conteúdos".

Desta maneira, alerta Davini, oportuniza-se aos alunos, em um processo de sucessivas aproximações, refletir e assimilar os conhecimentos programados para cada unidade.

Para percorrer metodologicamente este processo, optou-se pela linha do PLANEJAMENTO ESTRATÉGICO que não significa apenas uma afirmação das aspirações de uma empresa, pois inclui e deve ser feito para transformar essas aspirações em realidade.

O Planejamento Estratégico inclui duas dimensões: ELABORAÇÃO e IMPLEMENTAÇÃO.

$\mathrm{Na}$ fase de elaboração, volta-se os olhos para identificar e avaliar os pontos fortes e fracos do empreendimento, sua capacidade real e potencial, assim como, perceber e enfrentar as ameaças.

Nesta perspectiva, o autor indica duas possibilidades para se desenvolver um planejamento estratégico:

- primeiramente se define "onde se quer chegar" e depois se estabelece como se está, para se chegar na situação desejada; ou

- define-se inicialmente "como se está" e depois se estabelece "onde se quer chegar". 
Optamos nestas possibilidades pela forma de se recorrer ao planejamento estratégico abarcando as duas hipóteses, ou seja, determinar os objetivos "onde se quer ir", conhecendo e analisando a própria situação "onde se está".

Como o próprio planejamento estratégico sugere, a aplicação do processo metodológico fundamenta-se em fases básicas que vão dar conta da sua elaboração e implementação, o que se realiza a partir de:

1. diagnóstico estratégico;

2. missão da empresa;

3. instrumentos prescritivos e quantitativos;

4. controle e avaliação.

Seguindo esta trajetória, iniciamos a primeira fase do estudo do Currículo de Graduação de Enfermagem - UERJ, diagnosticando como condição precipua a "DESCONTEXTUALIZAÇÃO" do currículo vigente e os "NÓS" que enfrentamos para levar a cabo a proposta de Reforma Curricular, tão almejada pelos professores, alunos e comunidade que utilizam o Sistema de Saúde, cujo esquema apresentaremos a seguir:

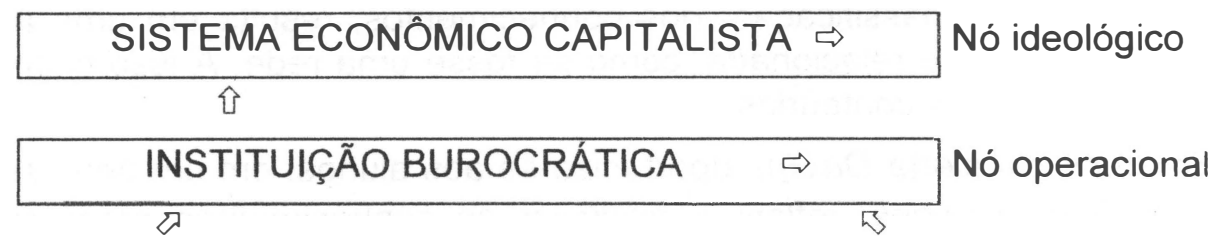

\section{CORPO DOCENTE COM VISÃO FUNCIONALISTAVTECNICISTA}

ת

Nó crítico
CURRÍCULO DEFASADO

Nó circunstancial

Q

CURRÍCULO DESCONTEXTUALIZADO

Após o diagnósticos dos problemas, foram instituídas as frentes de a : deverão ser percorridas no sentido de vencer os desafios identifirados e perseguir os objetivos de modo hierarquizado inicialmente, porém operacionalizados de maneira flexível e espontânea, procurando apoiar-se em idéias e debates, sem, no entanto, perder de vista os aspectos de rialidade, bem como o período de tempo estabelecido para a sua concretude.

Assim, neste caminhar, optamos por uma metodologia que nos permitisse avançar no delineamento de ações a partir das necessidades surgidas, cujos procedimentos fossem gerados no próprio processo ou, como diz Saul, percorrer 
uma "trilha metodológica" ${ }^{29}$ que não perdesse de vista a descrição e crítica da realidade e a construção coletiva, apropriando-se do método dialógico e dos princípios metodológicos nele contidos como norteadores de pistas a serem perseguidas.

Neste aspecto, traçamos algumas linhas de ação a serem percorridas no ano de 1995, a saber:

1. Implementação do Processo de Capacitação Pedagógica para professores que ainda não se capacitaram;

2. Realização de Oficinas de Trabalho, a partir das necessidades apontadas;

3. Levantamento do Perfil Profissional atual e o desejável, a partir da identificação dos desempenhos e comportamentos profissionais que vêm sendo ensinados e os que devem ser incorporados e/ou eliminados e dos principios científicos que sustentam os desempenhos;

4. Discussão, através de seminários, dos seguintes temas:

- Teoria Crítica da Educação;

- Pedagogia da Problematização;

- Currículo Integrado;

- Processo de Trabalho Enfermagem/Saúde;

- Perfil Epidemiológico;

- Integração Educação/Trabalho.

5. Sistematização dos desempenhos, comportamentos, habilidades e principios;

6. Definição do Perfil Profissional existente e daquele que se deseja incorporar;

7. Identificação das áreas de conhecimento que compõem o Currículo Integrado do Curso de Graduação em Enfermagem;

8. Localização das disciplinas afins dentro das áreas, articulando-as e deslocando-as para o mesmo período;

9. Promoção de um processo de articulação entre as disciplinas profissionalizantes;

10. Estruturação da REDE de conhecimentos por área, através da identificação e sistematização dos PRINCÍPIOS técnico-científicos, políticos e filosóficos e os CONCEITOS-CHAVE identificados como mais especificos, mais abrangentes e mais gerais;

11. Paralelamente, Capacitação Pedagógica dos professores de outras unidades que participam da formação do enfermeiro;

12. Promoção no Ciclo Básico das linhas de ação determinadas para o Ciclo Profissionalizante no que concerne aos itens 8, 9 e 10 acima descritos.

13. Reunião de esforços na tentativa de promover a integração do Ciclo Básico com o Profissionalizante. 


\section{CONSIDERAÇÕES FINAIS}

Quando concluimos esta etapa do trabalho, a elaboração do currículo integrado encontrava-se na fase 2 , descrita no Anexo I. Todavia, pretendemos, à medida em que as fases seguintes sejam concluídas, socializar esta experiência através de outros artigos.

O processo de construção de Currículo, apoiado por uma Teoria Crítica Problematizadora, tem sido como explorar um caminho, indo e vindo, superando obstáculos. A construção coletiva possibilita errar menos, a partir de uma experiência grupal essencialmente dialógica, apoiada nos ensinamentos de Paulo Freire, em seu livro A Pedagogia do Oprimido, que aqui resume o nosso trabalho:

"Não é no silêncio que os homens se fazem, mas na palavra, no trabalho, na ação-reflexão.

Por isso, o diálogo é uma exigência existencial. ... mas, não há diálogo, se não há uma profunda fé nos homens. Fé no seu poder de fazer e refazer; criar e recriar.

Fé na sua vocação de Ser Mais, que não é privilégio de alguns eleitos, mas direito dos homens". 


\section{ANEXO I - PLANEJAMENTO OPERACIONAL DA CONSTRUÇÃO DO CURRÍCULO INTEGRADO}

\begin{tabular}{|c|c|c|c|}
\hline PROPOSTAS REALIZADAS & ESTRATÉGIAS & CRONOGRAMA & RESPONSÁVEIS \\
\hline $\begin{array}{l}\text { 1. Capacitação pedagógica } \\
\text { do corpo docente do } \\
\text { Curso de Graduação de } \\
\text { Enfermagem }\end{array}$ & $\begin{array}{l}\text { Realização de curso em parceria com } \\
\text { a Escola de Formação Técnica em } \\
\text { Saúde - SES para os enfermeiros } \\
\text { docentes e preceptores. } \\
\text { Realização de Curso para os docen- } \\
\text { tes de outras Unidades da Uerj que } \\
\text { ministram disciplinas no Curso de } \\
\text { Graduação em Enfermagem. }\end{array}$ & $\begin{array}{l}\text { De } 1992 \text { a } 1995, \\
\text { nos meses de } \\
\text { recesso escolar } \\
1995 / 1996\end{array}$ & \\
\hline $\begin{array}{l}\text { 2. Institucionalização da } \\
\text { mudança do currículo do } \\
\text { Curso de Graduação }\end{array}$ & $\begin{array}{l}\text { - Constituição de um grupo de } \\
\text { trabalho } \\
\text { - Realização das Oficinas com o } \\
\text { grupo de trabalho para: } \\
\text {. Construção do paradigma da } \\
\text { educação/enfermagem / tra- } \\
\text { balho. } \\
\text { Elaboração do instrumento } \\
\text { para o levantamento do } \\
\text { perfil do enfermeiro } \\
\text { Elaboração do projeto para } \\
\text { cadastramento na SR-1, } \\
\text { SR-2 e CNPq } \\
\text {. Treinamento do grupo do cur- } \\
\text { rículo para aplicação do } \\
\text { instrumento } \\
\text {. Aprovação do projeto. }\end{array}$ & $\begin{array}{l}\text { Março / } 1995 \\
20 \text { a } 23 \text { de março } \\
\text { / } 1995 \\
\text { às } 2 \text { a feiras com- } \\
\text { preendidas entre } \\
27 / 03 \text { e } 24 / 04 / 95 \\
\text { Idem } \\
27 / 04 \text { a 04/05/95 }\end{array}$ & \\
\hline $\begin{array}{l}\text { 3. Construção do perfil } \\
\text { profissional do enfer- } \\
\text { meiro }\end{array}$ & $\begin{array}{l}\text { Realização de Oficina de Trabalho } \\
\text { com grupos de docentes e discentes } \\
\text { por área do saber para levantamento } \\
\text { dos desempenhos ensinados e dos } \\
\text { princípios que os apoiam: } \\
\text { - Enfermagem Básica } \\
\text { - Enfermagem Psiquiátrica } \\
\text { - Exercício de Enfermagem, Ética da } \\
\text { Enfermagem e Didática Aplicada à } \\
\text { Enfermagem } \\
\text { - Enfermagem Pediátrica e Enfer- } \\
\text { magem de Saúde Pública } \\
\text { - Enfermagem Neonatal } \\
\text { - Pesquisa em Enfermagem } \\
\text { - Enfermagem Cirúrgica } \\
\text { - Enfermagem Clínica } \\
\text { - Administração em Enfermagem } \\
\text { - Enfermagem em Unidade de Tra- } \\
\text { tamentos Especiais } \\
\text { - Enfermagem Ginecológica } \\
\text { - Enfermagem Obstétrica } \\
\text { - Enfermagem em Doenças Trans- } \\
\text { missíveis }\end{array}$ & $\begin{array}{l}08 \text { e } 25 / 05 / 95 \\
08 / 05 / 95 \\
10 / 05 / 95 \\
\\
10 / 05 / 95 \\
\\
12 / 05 / 95 \\
15 / 05 / 95 \\
17 \text { e } 24 / 05 / 95 \\
19 / 05 / 95 \\
23 / 05 / 95 \\
24 / 05 / 95 \\
\\
25 / 05 / 95 \\
25 / 05 / 95 \\
30 / 05 / 95\end{array}$ & \\
\hline
\end{tabular}




\begin{tabular}{|c|c|c|c|}
\hline PROPOSTAS REALIZADAS & ESTRATÉGIAS & CRONOGRAMA & RESPONSÄVEIS \\
\hline $\begin{array}{l}\text { 4. Desenvolvimento do } \\
\text { corpo docente e "nivela- } \\
\text { mento de conteúdos e/ ou } \\
\text { informações" }\end{array}$ & $\begin{array}{l}\text { Realização dos Seminärios sobre os } \\
\text { seguintes temas: } \\
\text { - Teoria Critica da Educação } \\
\text { - Pedagogia da Problematização } \\
\text { - Curriculo Integrado } \\
\text { - Processos de trabalho Enferma- } \\
\text { gem/Saúde } \\
\text { - Perfil Epidemiológico } \\
\text { - Integração Educação/Trabalho }\end{array}$ & $\begin{array}{l}\text { junho-julho } \\
\text { junho } \\
\text { junho }\end{array}$ & \\
\hline $\begin{array}{l}\text { 5. Construção do Currículo } \\
\text { Integrado }\end{array}$ & $\begin{array}{l}\text { Realização das OFICINAS para: } \\
\text { - Sistematizar os desempenhos, os } \\
\text { comportamentos, as habilidades } \\
\text { e os princípios } \\
\text { - Identificar as áreas que compõem o } \\
\text { curriculo integrado } \\
\text { - Localizar as disciplinas afins dentro } \\
\text { das áreas, articulando-as e deslo- } \\
\text { cando-as para o mesmo periodo } \\
\text { - Promover o processo de articulação } \\
\text { entre as disciplinas profissiona- } \\
\text { lizantes } \\
\text { Estruturar a rede de conheci- } \\
\text { mento por área através da } \\
\text { identificação e sistematização } \\
\text { dos princípios técnico-cientíri- } \\
\text { vos, políticos e filosóficos e } \\
\text { conceitos-chave mais especifi- } \\
\text { cos, mais abrangentes e mais } \\
\text { gerais. }\end{array}$ & $\begin{array}{l}\text { junho } \\
\text { julho } \\
\text { agosto } \\
\text { agosto/setembro } \\
\text { outubro }\end{array}$ & $\begin{array}{l}0 \text { grupo de trabalho } \\
0 \text { grupo de trabalho } \\
\text { Todos os docentes da FENF com a } \\
\text { participação do alunado } \\
\text { Idem } \\
0 \text { grupo de trabalho e docentes }\end{array}$ \\
\hline $\begin{array}{l}\text { 6. Capacitação Pedagógica } \\
\text { dos docentes de outras } \\
\text { Unidades }\end{array}$ & $\begin{array}{l}\text { Promoção de ampla discussão e } \\
\text { capacitação pedagógica dos profes- } \\
\text { sores de outras Unidades que parti- } \\
\text { cipam da formação do enfermeiro. }\end{array}$ & junho a dezembro & \\
\hline
\end{tabular}




\section{ANEXO II - LEVANTAMENTO DO PERFIL PROFISSIONAL DO CURSO DE GRADUAÇÃO EM ENFERMAGEM FACULDADE DE ENFERMAGEM / UERJ}

\begin{tabular}{|c|c|}
\hline SEQÜÊNCIA DE ATIVIDADES & ORIENTAÇÕES PARA O DESENVOLVIMENTO DAS ATIVIDADES \\
\hline $\begin{array}{l}\text { 1. Discutir o entendimento que o grupo possui a respeito } \\
\text { dos "desempenhos" profissionais em Enfermagem: }\end{array}$ & $\begin{array}{l}\Rightarrow \text { Levar o grupo a explicitar sua compreensão acerca do que } \\
\text { significa "desempenho profissional" (registre-os no papel } \\
\text { "kraft") }\end{array}$ \\
\hline $\begin{array}{l}\text { 2. Buscar extrair um conceito sintese do grupo; sistemati- } \\
\text { zando-o; }\end{array}$ & $\begin{array}{l}\Rightarrow \text { Promover a análise dos conceitos enunciados (levantando os } \\
\text { pontos comuns e as diferenças) visando a identificação das } \\
\text { "especificidades" da prática do Enfermeiro. }\end{array}$ \\
\hline $\begin{array}{l}\text { 3. Enumerar os desempenhos profissionais que vém sendo } \\
\text { ensinados na àrea de conhecimento e que ajudam a for- } \\
\text { mar o perfil profissional do Enfermerro: }\end{array}$ & $\begin{array}{l}\Rightarrow \text { Solicitar que o grupo elabore um elenco dos desempenhos } \\
\text { "objetivamente" ensinados. }\end{array}$ \\
\hline $\begin{array}{l}\text { 3a. Descrever Quaıs as habilidades elou } \\
\text { comportamentos que vèm sendo ensinados na área } \\
\text { de conhecimento e que ajudam a delinear o perfil } \\
\text { profissional do Enfermeiro; }\end{array}$ & $\begin{array}{c}\Rightarrow \text { Esta questão é destinada àquelas áreas de conhecimento em } \\
\text { Enfermagem que não geram necessariamente uma "ação" de } \\
\text { Enfermagem, mas que são fundamentais para guiar as ações } \\
\text { próprias do Enfermeiro (ética, exercicio, história, pesquisa). }\end{array}$ \\
\hline $\begin{array}{l}\text { 4. Destacar os desempenhos "desejáveis" a serem mantidos } \\
\text { e aqueles a serem incorporados à sua área, tambem os } \\
\text { considerados "inadequados" à prática de Enfermagem } \\
\text { na atualidade: }\end{array}$ & $\begin{array}{c}\Rightarrow \text { Orientar o grupo para considerar a realidade social e sanitária } \\
\text { (desenvolvimento econômico, condições sociais, tecnológicas, } \\
\text { processo de trabalho, organização dos serviços, etc). }\end{array}$ \\
\hline $\begin{array}{l}\text { 5. Identificar quais os principios técnico-cientificos que } \\
\text { sustentam os desempenhos enumerados na atividade } 3 \text {. }\end{array}$ & $\begin{array}{l}\Leftrightarrow \text { Registrar no papel "kraft", relacionando-os com os desempe- } \\
\text { nhos enumerados na atividade } 3 \text {. }\end{array}$ \\
\hline
\end{tabular}




\section{REFERÊNCIAS BIBLIOGRÁFICAS}

1. ASSOCIAÇÃO BRASILEIRA DE ENFERMAGEM. Perfil e competência do enfermeiro e o currículo mínimo para a Graduação em Enfermagem. ANAIS do Seminário da região Sudeste. São Paulo: 1988.

2. Currículo mínimo para a formação do enfermeiro. Seminário Nacional. CEEnf. SESU-MEC. Rio de Janeiro, Niterói, 1989.

3. Proposta de novo currículo para o Curso Superior de Enfermagem: a formação do enfermeiro. Brasília: 1991.

4. AZEVEDO, Maria Lúcia. "Educação de trabalhadores da enfermagem com enfoque na pedagogia da problematização: Avaliação de uma experiência no Rio de Janeiro. Rio de Janeiro, 1991. Dissertação de mestrado FE-UERJ.

5. BARDIN, Laurence. Análise de conteúdo. São Paulo: Edição 70 PERSONA, 1979, 225p.

6. BRANDÃO, C.R. Avaliação, participação-anotações sobre um ritual de fim de período. Cadernos Cedes, n.12, p.57-64,1984.

7. BRASIL, Ministério da Saúde. VIII Conferência Nacional de Saúde Relatório Final - Brasília: 1986.

8. BRASIL, Instituto Nacional de Assistência Médica da Previdência Social. Secretaria de Medicina Social. Distrito Sanitário: contribuição para um novo tipo de atendimento dos serviços de Saúde. 2. ed. Rio de Janeiro: Coordenadoria de Comunicação Social do INAMPS, 1988. 36 p.

9. BRASIL, Ministério da Saúde. Capacitaçāo pedagógica para instrutor/supervisor - Área da Saúde. Brasilia: Secretaria de Recursos Humanos, 1989.

10. BRASIL, Ministério da Saúde. $A B C$ do SUS - Doutrinas e Princípios. Brasília: Secretaria Nacional de Assistência á Saúde, 1990. 20 p.

11. BRASIL, Ministério da Saúde. Lei Orgânica da Saúde - 2. ed. Brasília: Assessoria de Comunicação Social, 1991. 36 p.

12. BRASIL, Ministério da Saúde. IX Conferência Nacional de Saúde. Brasilia: 1993. 
13. CONSELHO FEDERAL DE EDUCAÇÃO. Currículo minimo para a graduação em enfermagem. Parecer 314/94. Exposição de motivos do Relator Virgínio Cândido Tosta de Souza. Brasilia. DOU de 20/11/1994.

14. CHRISTÓfARO, Maria Auxiliadora C. A organização do sistema educacional brasileiro e a formação na área de saúde: documento do programa de recursos humanos. OPAS/BRASIL. Brasilia, 1992.

15. DÂMASO, Romualdo Francisco et al. A instituição de avaliação no ensino de Enfermagem. R. Enfermagem - UERJ, Rio de Janeiro. v. 2. n. 2, p. 212-220 - out.1994.

16.

A justiça cuidadosa: introdução à análise institucional de ensino de Enfermagem. R. Enfermagem UERJ. Rio de Janeiro, v. 2, n. 1, p. 3-12, maio 1994.

17. DEMO, Pedro - Avaliação qualitativa. 2. ed. São Paulo: Cortez. 1988

18. FREIRE, Paulo e SHOR, Ira. Medo e Ousadia : o cotidiano do professor. Rio de Janeiro: Paz e Terra, 1986.

19. FUNDAÇÃO OSWALDO CRUZ - Dados Radis, dez. 1990.

20. GERMANO, Raimunda M. Educação e ideologia da enfermagem no Brasil. São Paulo: Cortez, 1983.

21. GOOD, William J., HATT, Paul K. Métodos em pesquisa social. $7^{\mathrm{a}}$ ed. São Paulo: Ed. Nacional, 1979, 488 p.

22. GIROUX, Henry. Teoria crítica e resistência em educação. Para além das teorias de reprodução. Rio de Janeiro: Ed. Vozes, 1986.

23. KOSIK, Karel. Dialética do Concreto. Rio de Janeiro. Ed. Paz e Terra, 1986.

24. LOPES, Gertrudes T., CALDAS, Nalva P, SILVA, Maria Therezinha N., VIANNA, Luiz Cesar L. Perfil dos egressos da Faculdade de Enfermagem da UERJ: estudo preliminar. Rio de Janeiro, 1994.

25. LUDKE, Menga, ANDRÉ, Marli, E. D. A. Pesquisa em Educação: abordagens qualitativas. São Paulo: EPU, 1986, 99p.

26. MINISTÉRIO DA SAÚDE - AIDS. Boletim Epidemiológico. Ano VIII, n. 1, dez. 94, jan. e fev. 1995. 
27. MINISTÉRIO DA SAÚDE. Formação Superior em Saúde: Tendências da graduação no periodo 1985/1991. Cadernos de Recursos Humanos em Saúde. Ano 1, v. 1, n. 2, 1993.

28. PIERANTONI, Célia R., MACHADO, Helena M. Profissões de Saúde: a formação em questão. II Conferência Nacional de Recursos Humanos. Cadernos de Recursos Humanos em Saúde. Ano 1, v. 1, n. 3. Brasília: 1993.

29. SAUL, Anamaria. Avaliação Emancipatória: desafio à teoria e à prática de avaliação e reformulação de currículo. 2. ed. São Paulo: Cortez. 1991.

30. SAVIANI, Demerval. Tendências pedagógicas na prática escolar. Revista da ANDES, n. 6, 1982.

31. TRIVIÑOS, Augusto R. S. Introdução à pesquisa em ciências sociais. São Paulo: Atlas, 1987, 175 p. 